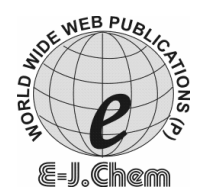

http://www.e-journals.net
ISSN: 0973-4945; CODEN ECJHAO

E-Journal of Chemistry 2009, 6(4), 985-992

\title{
Investigation of Charge Transfer Complex Formation Between Fe(III) and 2,6-Dihydroxy Benzoic Acid and its Applications for Spectrophotometric Determination of Iron in Aqueous Media
}

\author{
MOHAMMAD SAEID HOSSEINI* ${ }^{*}$ and SARA MADARSHAHIAN \\ Department of Chemistry, \\ Faculty of Science, Birjand University, Birjand, P.O. Box 414, Iran. \\ mshosseini@birjand.ac.ir
}

Received 14 December 2008; Accepted 25 February 2009

\begin{abstract}
On the basis of affinity of $\mathrm{Fe}(\mathrm{III})$ ions toward functional groups of 2,6-dihydroxy benzoic acid (2,6-DHB), a charge transfer complex (CT) is formed between $\mathrm{Fe}(\mathrm{III})$ ion and 2,6-DHB in acidic media. The stoichiometry and stability constant of the complex was determined using both mole ratio and Job's methods. The stability constant of 1:1 complex formed in acidic media is $2.55 \pm 0.14 \times 10^{5}$ (mole ratio) or $2.70 \pm 0.12 \times 10^{5}(\mathrm{Job})$, in which the quantities are in agreement with together. This method was used for spectrophotometric determination of $\mathrm{Fe}(\mathrm{III})$ in aqueous media. The dynamic range and detection limit (DL) were $1.2 \times 10^{-5}$ to $3.6 \times 10^{-4} \mathrm{M}$ and $1.5 \times 10^{-6} \mathrm{M}$, respectively. The relative standard deviation (RSD) was found to be $0.76 \%$ in the replicate treatments $(\mathrm{n}=7)$ with $1.6 \times 10^{-4} \mathrm{M} \mathrm{Fe}(\mathrm{III})$. The practical applicability of the method was confirmed using a synthetic certificated reference material (CRM) and spiked natural water samples.
\end{abstract}

Keywords: Charge transfer complex, 2,6-Dihydroxybenzoic acid, Fe(III), Spectrophotometry, Mole ratio and Job's method

\section{Introduction}

Owing to simplicity, lesser expensive instrumentation and provides high versatility UVVisible spectrophotometric methods have been developed for the determination of metal ions. It involves using a number of chromogenic reagents for this purpose. Ferric ion is the most stable state of iron in the solutions, hence the determination of iron is generally demonstrated on $\mathrm{Fe}(\mathrm{III})$ contents. In recent years, numerous chromogenic reagents, which capable to form high stable complexes with Fe(III) ion, have been widely used for the 
determination of iron contents in numerous complicated matrices ${ }^{1-7}$. Among the various reagents that was used, it was found the reagents that capable to form charge transfer (CT) complexes with $\mathrm{Fe}(\mathrm{III})$, exhibit more sensitivity for such determination, specially in treatment with the trace amount of $\mathrm{Fe}(\mathrm{III})$ ions.

Apparently, presence of $\mathrm{Fe}(\mathrm{III})$ in the environmental samples is contributed to construction of high stable complexes with the natural products, such as humic compounds. In order to characterize the structure of such complexes, a number of studies performed on the complexes constructed from Fe(III) and simple humic models, both in solution and in the solid state $^{8-11}$. In view of this considerations, the 2,6-dihydroxy benzoic acid (2,6-DHBA) is one of the most interesting reagent because of presence two hydroxyl groups adjacent to the carboxy1 group in its molecular structure. It is easily soluble in water, in spite of presence of two strong intra molecular hydrogen bonds in its structure ${ }^{12-14}$. It was found from the NMR investigation that there is a fast (in NMR scale) degenerate equilibrium between the two tautomer structures involving the double proton transfer. This phenomenon causes to form stable complexes between 2,6-DHB and some metal ions ${ }^{15-24}$. Among them, the CT complexes exhibit more stability and absorptivity. In this work, the CT complex of Fe(III)-2,6-DHB was synthesized and characterized by spectrophotometric methods. At the following, it was applied for spectrophotometric determination of trace amount of Fe(III) ions in aqueous solutions.

\section{Experimental}

A Shimadzu model 160A spectrophotometer was used for the absorbance measurements with one pair of 10-mm quartz cell. A Corning model $125 \mathrm{pH}$ meter was used for the $\mathrm{pH}$ adjustment. For plotting the curves and obtaining their equations, Grapher version 1.09 program was employed.

All solutions were prepared using deionized and double distilled water. An approximately $0.1 \mathrm{M}$ solutions of 2,6-DHBA, obtained from Fluka (Switzerland), and $\mathrm{Fe}\left(\mathrm{NO}_{3}\right)_{3}$, obtained from Merck (Germany), were prepared and standardized against KOH Titrisol and Titriplex® III solutions, respectively. The working solutions were made by suitable dilution of these standard solutions. Both the standard and working solutions were stored in PTFE bottles. The buffer solution required to adjust the $\mathrm{pH}$ of the solutions were prepared by mixing $1 \mathrm{M}$ formic acid/sodium formate and acetic acid/sodium acetate (all the reagents obtained from Merck) for the $\mathrm{pH}$ range of 2.5-3.5 and 3.5-5.5, respectively. The other reagents were of analytical grade, obtained from Merck, and were used without further purification.

Spectrophotometric determination of $\mathrm{Fe}(\mathrm{III})$ ions

To a solution containing up to $0.5 \mathrm{mg}$ of $\mathrm{Fe}(\mathrm{III})$ ions, $0.5 \mathrm{~mL}$ of $0.05 \mathrm{M}$ 2,6-DHB solution was added and its $\mathrm{pH}$ was adjusted to $3.00 \pm 0.05$ using formic acid/sodium formate solutions. The solution was diluted to the mark using a $25 \mathrm{~mL}$ volumetric flask. It was shaken for a few minutes and finally the absorbance was measured at $560 \mathrm{~nm}$ against a reagent blank prepared by the same manner.

\section{Results and Discussion}

Characterization of the complex formation

The proposed method involves formation of soluble bluish CT complex. As shown in Figure 1, the product exhibits a maximum absorption in the visible region on $560 \mathrm{~nm}$ against the reagent blank, whereas both the reactants show negligible absorption at this wavelength interval, solitarily. Consequently, the absorbance is directly related to the complex construction, which is made greater by increasing both the concentration and $\mathrm{pH}$ of the solution. Obviously, there is a risk of precipitate the $\mathrm{Fe}(\mathrm{III})$ content as hydroxide, when the $\mathrm{pH}$ is so 
increased. As it is shown in Figure 1, this phenomenon causes to decrease the absorbance at the $\mathrm{pH}$ more than 3 . Hence, the future examinations were carried out at the buffering $\mathrm{pH}$ of $3 \pm 0.05$ as the optimum $\mathrm{pH}$ for such determinations.

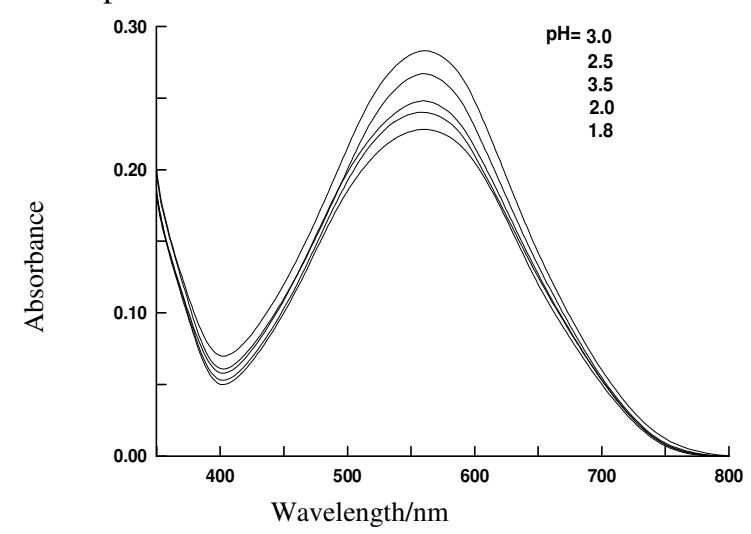

Figure 1. Effect of $\mathrm{pH}$ on complex formation at the conditions in which the concentration of $\mathrm{Fe}$ (III) and 2,6-DHB were equal to $1.5 \times 10^{-4} \mathrm{M}$, and the absorbance measurements were carried out at $560 \mathrm{~nm}$ as the maximum wavelength.

The effect of 2,6-DHB concentration on the complex formation was examined in the range of $0-6 \times 10^{-4} \mathrm{M}$ using the solutions in which the concentrations of $\mathrm{Fe}(\mathrm{III})$ were fixed on $1.2 \times 10^{-4} \mathrm{M}$. As shown in Figure 2, the absorbance measurements established that the requested ligand concentration to complete the complex formation should be at least three times of $\mathrm{Fe}(\mathrm{III})$ concentration. Furthermore, it should be considered that the reaction between $\mathrm{Fe}(\mathrm{III})$ and 2,6-DHB tends to complete more rapidly at the presence of excess amount of the ligand.

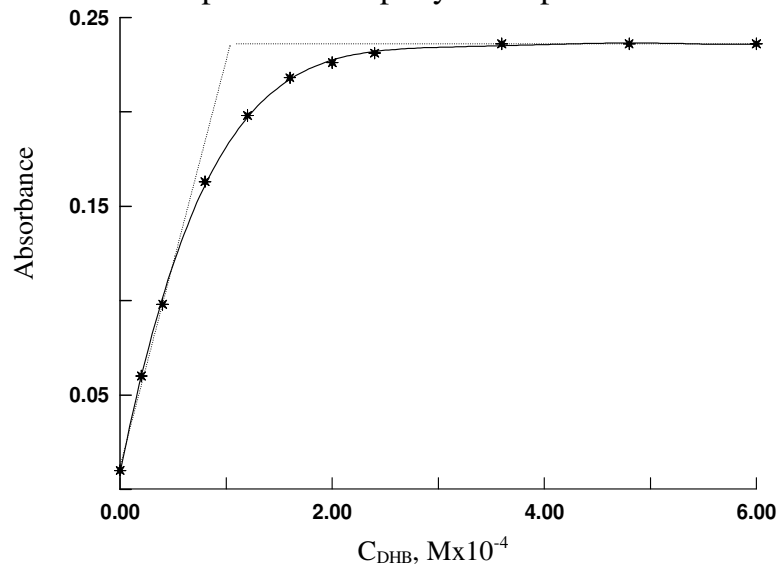

Figure 2. The mole ratio plot that was fitted as equation of $A=0.000201141 C^{5}-0.00423842$ $\mathrm{C}^{4}+0.0349676 \mathrm{C}^{3}-0.141571 \quad \mathrm{C}^{2}+0.283276 \mathrm{C}+0: 0.00874717, \quad\left(\mathrm{r}^{2}: 0.999635\right)$. The extrapolated Equations: $\mathrm{A}=0.215002 \mathrm{C}+0.012333$; $\mathrm{A}=7.28825 \times 10^{-018} \mathrm{C}+0.236$. The experimental conditions were as follows: $\mathrm{Fe}(\mathrm{III})=1.2 \times 10^{-4} \mathrm{M}, \mathrm{pH}=3, \lambda \max _{\max }=560 \mathrm{~nm}$, and concentration of 2,6-DHB was increased up to $6.0 \times 10^{-4} \mathrm{M}$.

In order to investigate the effect of non aqueous medium on formation of the complex, a series of mixed methanol-water solutions containing 20,40 and $60 \%$ methanol were prepared in which the concentrations of $\mathrm{Fe}(\mathrm{III})$ and 2,6-DHB were fixed on $1.2 \times 10^{-4} \mathrm{M}$ and 
$3.6 \times 10^{-4} \mathrm{M}$, respectively. It was found that the absorbance values from 0.203 respects to aqueous solution were increased up to 0.245 for $60 \%$ methanol. With regards to this observation, occurrence of the charge transfer phenomenon, which is enhanced by decreasing the polarity of the solvent, was confirmed.

\section{Determination of the complex formation by mole ratio method}

In order to calculate formation constant of the complex by using the mole ratio method ${ }^{25}$, the solutions that were prepared to investigate the effect of 2,6-DHB concentration on the complex formation was used for this purpose. As it is shown in Figure 2, the break point arising from the extrapolated tangent lines of the curve confirms that $2,6-\mathrm{DHB} / \mathrm{Fe}$ (III) ratio in the CT complex is $1: 1$. By considering to the equation curve fitted to the spectrophotometric data, the absorbance value at 1:1 ratio in which the CT complex is in equilibrium with the metal/ligand constituents, is directly related to the complex concentration. By using the molar absorptivity of the complex that was obtained from the linear calibration curve, the complex concentration is calculated and consequently, the metal and ligand concentrations were determined by subtracting from the initial ligand quantity $\left(1.2 \times 10^{-4} \mathrm{M}\right)$. In this manner, the formation constant was found to be $2.55 \pm 0.14 \times 10^{5}$.

\section{Determination of the complex formation by Job's method}

In order to confirm the determination of the complex formation constant obtained from the mole ratio method, the calculation was repeated by using the Job's method ${ }^{26}$. Subsequently, a series of $25 \mathrm{~mL}$ solutions $(\mathrm{n}=21)$ were prepared in which the Fe(III) and 2,6-DHB contents were just inversely varied over the concentration range of 0 to $4.0 \times 10^{-4} \mathrm{M}$ so that the total mole fractions were fixed to 1 . The $\mathrm{pH}$ of the solutions was adjusted to $3.00 \pm 0.05$ by addition of adequate quantities of formic acid / sodium formate solutions. The solutions were then transferred to $25 \mathrm{~mL}$ volumetric flasks and diluted to the mark. After shaking them for a few minutes, the absorbance values were measured at $560 \mathrm{~nm}$ against the buffering blank containing formic acid / sodium formate solutions. Figure 3 represents variation of absorbance (A) vs. mole fraction of 2,6-DHB reagent. As it is shown, the maximum absorbance was obtained within the range of $0.45-0.50$, which denotes that $\mathrm{Fe}(\mathrm{III}) / 2,6-\mathrm{DHB}$ ratio in the CT complex is $1: 1$. According to the discussion present in the literature $^{27}$, a little deviation observed between the experimental and theoretical values is predictable, which is attributed to the dissociation phenomenon of 2,6-DHB. Curve 1 in Figure 3, represents extrapolation of the linear sections of curve 2. By intersecting the extrapolated lines equations, the coordination of the break point was obtained as $A_{1}=0.354$ and $\mathrm{X}_{\mathrm{L}}=0.50$. This break point locates situation in which dissociation of the complex is negligible. The normal maximum absorbance with coordination of $\mathrm{A}_{2}=0.309 \pm 0.001$ and $\mathrm{X}_{\mathrm{L}}=0.50$, was considered as the maximum point of curve 2 . Essentially, the $\mathrm{A}_{1}$ and $\mathrm{A}_{2}$ should be obtained at an equal mole fraction value of 2,6-DHB. Hence, the mole fraction respected to $A_{1}$ was inserted in equation of curve 2 and the resulted absorbance was considered as $A_{2}$ value. The complex formation constant, $K_{f}$, was then calculated from the following equation:

$$
\mathrm{K}_{\mathrm{f}}=\frac{A_{2} / A_{1}}{C_{M}\left(1-A_{2} / A_{1}\right)^{2}}
$$

where, $C_{M}$ is the initial analytical concentration of $\mathrm{Fe}(\mathrm{III})$ at the maximum points of $\mathrm{A}_{1}$ and $\mathrm{A}_{2}$. In this manner, the $\mathrm{K}_{\mathrm{f}}$ was obtained as $2.70 \pm 0.12 \times 10^{5}$. No significance difference was observed using the $\mathrm{F}$ and $\mathrm{t}$ tests at $95 \%$ confidence level between the two values obtained from both the above techniques. 


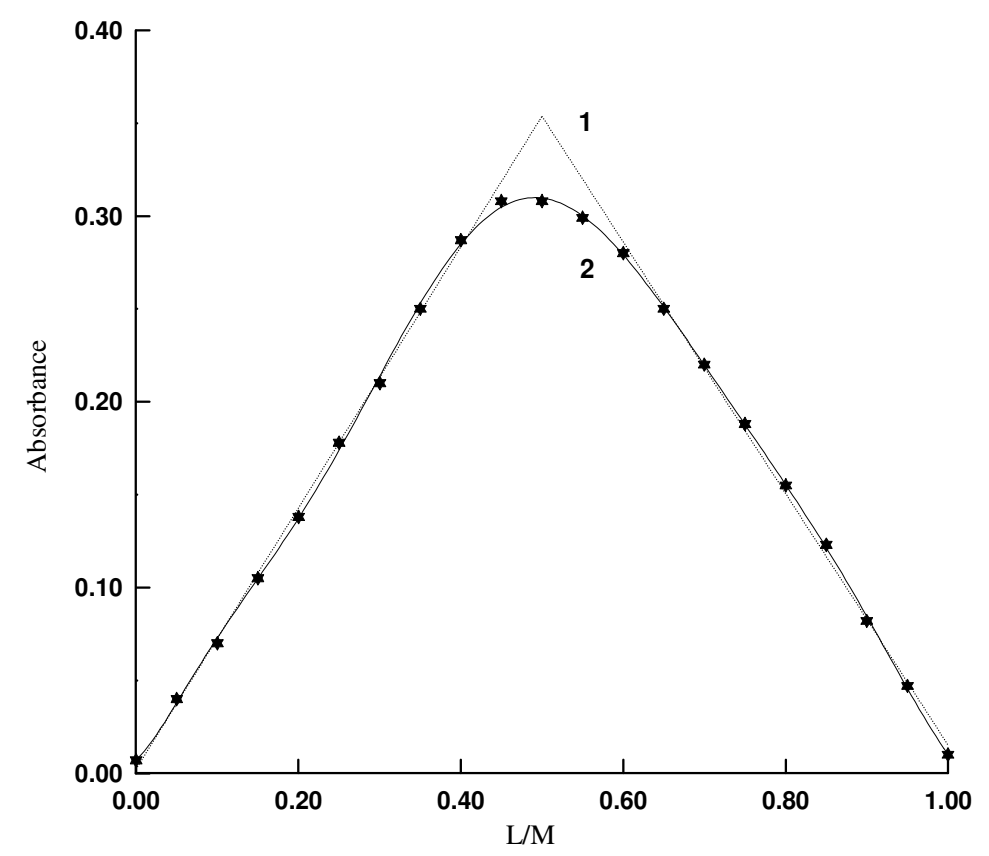

Figure 3. The continuous variation plot that was fitted as equation of $A=-167.609 C^{9}+$ $867.991 C^{8}-1848.76 C^{7}+2081.33 C^{6}-1321.74 C^{5}+468.375 C^{4}-87.9294 C^{3}+7.97288 C^{2}$ $+0.381383 \mathrm{C}+0.0074236,\left(\mathrm{r}^{2}=0.999588\right)$. The extrapolated equations: $\mathrm{A}=-0.677055 \mathrm{C}+$ $0.692218 ; \mathrm{A}=0.702807 \mathrm{C}+0.00233091$. The experimental conditions were similar to the mole ratio method except $\mathrm{Fe}$ (III) and 2,6-DHB contents were just inversely varied over the concentration range of 0 to $4.0 \times 10^{-4} \mathrm{M}$.

\section{Analytical figures of merit}

Under the optimum conditions, a linear calibration curve was constructed with equation of $\mathrm{A}=1966.7 C+0.0053,\left(\mathrm{r}^{2}=0.9987\right)$, for the determination of $\mathrm{Fe}(\mathrm{III})$ over the concentration range of $1.2 \times 10^{-5}$ to $3.6 \times 10^{-4} \mathrm{M}\left(0.28-20 \mu \mathrm{g} \mathrm{mL}^{-1}\right)$. The RSD obtained in the replicate treatments $(\mathrm{n}=7)$ with $1.6 \times 10^{-4} \mathrm{M} \mathrm{Fe}(\mathrm{III})$ was found to be $0.76 \%$. In treatment with the blank solutions, the DL was obtained as $1.5 \times 10^{-6} \mathrm{M}$.

\section{Effect of foreign ions}

The effects of several foreign ions were studied by introducing each one to $25 \mathrm{~mL}$ aliquots of the solutions containing $\mathrm{Fe}(\mathrm{II})$ with the concentration of $5.0 \times 10^{-5} \mathrm{M}$. Each ion was considered as interfering agent, when the absorbance value exhibited a deviation more than $\pm 5 \%$. It was found that 200 -fold excess of the alkaline and alkaline earth metal ions as chloride or nitrate compounds did not interfere in the determination of Fe(III) content. As shown in Table 1, some of the other metal ions were tolerated at moderately high foreign ion $/ \mathrm{Fe}(\mathrm{III})$ ratios.

\section{Application}

In order to test accuracy of the method, a laboratory synthetic wastewater was prepared by following the general considerations on preparation of a water certified reference material $(\mathrm{CRM})^{28}$. The major and minor constituents of the prepared sample, which were adjusted according to the details of No. 9 "Sargasso" CRM sample, are detailed in Table 2. 
Table 1. Tolerance ratio of the foreign ions on the determination of $5 \times 10^{-5} \mathrm{M}$ of $\mathrm{Fe}(\mathrm{III})$ in $25 \mathrm{~mL}$ of the aqueous phase.

\begin{tabular}{cl}
$\begin{array}{c}\text { Mole ratio of interfering } \\
\text { ion to } \mathrm{Ag}(\mathrm{I})\end{array}$ & \multicolumn{1}{c}{ Ions } \\
\hline 100 & $\mathrm{Zn}(\mathrm{II}), \mathrm{Co}(\mathrm{II}), \mathrm{La}(\mathrm{III}), \mathrm{Cd}(\mathrm{II}), \mathrm{Cu}(\mathrm{II}), \mathrm{Ca}(\mathrm{II})$, \\
& $\mathrm{Hg}(\mathrm{II}), \mathrm{As}(\mathrm{III}), \mathrm{Pb}(\mathrm{II}), \mathrm{Ce}(\mathrm{III}), \mathrm{Ni}(\mathrm{II})$, \\
50 & $\mathrm{Ag}(\mathrm{I}), \mathrm{Ce}(\mathrm{III})$, \\
10 & $\mathrm{Mn}(\mathrm{II}), \mathrm{Al}(\mathrm{III}), \mathrm{Cr}(\mathrm{III}), \mathrm{V}(\mathrm{III})$, \\
\hline
\end{tabular}

Table 2. Analytical values for NIES certified Reference Material No. 9 "Saragasso"

\begin{tabular}{llll}
\hline Major and minor constituents & & \multicolumn{2}{c}{ Trace costituents } \\
\hline Element & Content, wt.\% & Element & Content, $\mu \mathrm{g} / \mathrm{g}$ \\
\hline Calcium & $1.34 \pm 0.05$ & Iron & $187 \pm 6$ \\
Sodium & $1.70 \pm 0.08$ & Arsenic & $115 \pm 9$ \\
Potassium & $6.10 \pm 0.20$ & Rubidium & $24 \pm 2$ \\
Strontium & $0.100 \pm 0.003$ & Manganese & $21.2 \pm 1.0$ \\
Magnesium & $0.65 \pm 0.03$ & Zinc & $15.6 \pm 1.2$ \\
& & Copper & $4.9 \pm 0.2$ \\
& & Lead & $1.35 \pm 0.05$ \\
& & Vanadium & $1.0 \pm 0.1$ \\
& & Silver & $0.31 \pm 0.02$ \\
& & Cadmium & $0.15 \pm 0.02$ \\
& & cobalt & $0.12 \pm 0.01$ \\
\hline
\end{tabular}

Table 3. Comparison of the result obtained from this work with that of FAAS for the determination of $\mathrm{Fe}$ (III) in various environmental samples. The results are reported as the average values from five sample measurements with the related standard deviations.

\begin{tabular}{lcllll}
\hline \multirow{2}{*}{ Samples } & \multirow{2}{*}{ Spiked, $\mu \mathrm{g}$} & \multicolumn{2}{c}{ Found, $\mu \mathrm{g}$} & $f$ test value & $t$ test \\
\cline { 3 - 6 } & & This work & FAAS & Crit./Exp. & Crit./ Exp. \\
\hline Multi.-multi. & - & $174 \pm 1.7$ & $187 \pm 2.3$ & $6.39 / 1.83$ & $2.31 / 2.02$ \\
Tablet $^{\mathrm{a}}$ & 56 & $232 \pm 1.5$ & $240 \pm 2.6$ & $6.39 / 3.00$ & $2.31 / 2.12$ \\
& 56 & $58.3 \pm 0.6$ & $57.2 \pm 0.4$ & $6.39 / 2.25$ & $2.31 / 0.5$ \\
Tap water & 56 & $59.7 \pm 0.8$ & $58.4 \pm 0.4$ & $6.39 / 4.00$ & $2.31 / 0.6$ \\
Well water & - & $21.3 \pm 0.4$ & $22.8 \pm 0.6$ & $6.39 / 2.25$ & $2.31 / 0.5$ \\
Waste water & 28 & $50.3 \pm 0.5$ & $50.8 \pm 0.7$ & $6.39 / 1.96$ & $2.31 / 0.6$ \\
\hline
\end{tabular}

a: A multivitamin-multimineral tablet formula: VA, $5000 \mathrm{U} ; \mathrm{VD}, 400 \mathrm{U} ; \mathrm{VE}, 30 \mathrm{U} ; \mathrm{VB1}, 1.5 \mathrm{mg} ; \mathrm{VB2}, 1.5$ mg; VB6, $2 \mathrm{mg}$; VC, $60 \mathrm{mg}$; VB12, $6 \mu \mathrm{g}$; VKl, $25 \mu \mathrm{g}$; biotin, $30 \mu \mathrm{g}$; folic acid, $400 \mu \mathrm{g}$; niacinamide, 20 mg; pantothenic acid, $10 \mathrm{mg}$; Ca, $162 \mathrm{mg}$;, $125 \mathrm{mg}$; K, $40 \mathrm{mg}$; Cl, $36.3 \mathrm{mg} ; \mathrm{Fe}, 18 \mathrm{mg}$; Cu, $2 \mathrm{mg} ; \mathrm{Zn}$, $15 \mathrm{mg}$; Mn, $25.5 \mathrm{mg}$; I, $150 \mu \mathrm{g}$; Mo, $25 \mu \mathrm{g}$; Se, $25 \mu \mathrm{g} ; \mathrm{Ni}, 5 \mu \mathrm{g} ; \mathrm{Si}, 10 \mu \mathrm{g} ; \mathrm{Sn}, 10 \mu \mathrm{g} ; \mathrm{V}, 10 \mu \mathrm{g}$.

The recovery of $\mathrm{Fe}$ (III) was $95.4 \%$, which confirmed accuracy of the method. After that, the proposed method was applied to the determination of iron in a multivitaminmultimineral tablet and water samples including tap, well and industrial waste obtained from a chemical industry. The multivitamin-multimineral tablet was dissolved in $25 \mathrm{~mL}$ of $1 \mathrm{M}$ nitric acid and after heating the solution for $10 \mathrm{~min}$, it was diluted to the mark in a $1000 \mathrm{~mL}$ volumetric flask. Aliquots of $10 \mathrm{~mL}$ of this solution was applied to the determination process. In treatment with the water sample, they were initially filtered through a membrane 
filter with pore size of $0.45 \mu \mathrm{m}$. To confirm the accuracy of the results obtained by this method, the measurements were also repeated by a well-known method, such as FAAS ${ }^{29}$. The results for the determination and recovery of Fe(III) contents are shown in Table 3. As it is shown, the results obtained from both the methods were agreed with together according to $\mathrm{F}$ and $\mathrm{t}$ tests. These results are denoted with the applicability of this method for properly determination of $\mathrm{Fe}(\mathrm{III})$ in various water samples and similar sample solutions.

\section{Conclusion}

A new type of complex as a CT complex of Fe(III)-2,6-DHP was developed for determination of iron with spectrophotometric method. The Fe(III)-2,6-DHP complex benefits from a moderately high formation constant in acidic media. The proposed method provides an appropriate selectivity and sensitivity for easy determination of $\mathrm{Fe}$ (III) ions. One of the advantages of this method is directly measuring of $\mathrm{Fe}(\mathrm{III})$ in various aqueous media, such as pharmaceutical samples. A number of metal ions, which may be found either in water or pharmaceutical samples, did not interfere in the determination. The RSD and DL of the proposed method were respectively $0.76 \%$ and $1.5 \times 10^{-6} \mathrm{M}$, which are less than the respected values for iron determination by traditional direct spectrophotometric method, such as $\mathrm{Fe}$ (II)-1,10-phenanthroline. Furthermore, the method benefits form a widespread dynamic range in comparison with the above method and FAAS.

\section{References}

1. Tuzen M, Soylak M and Elci L, Anal Chim Acta., 2005, 548, 101.

2. Nascimento P C, Jost C L, Guterres M V, Del' Fabro L D, de Carvalho L M and Bohrer D, Talanta, 2006, 70, 540.

3. Pojanagaroon T, Watanesk S, Rattanaphani V and Liawrungrath S, Talanta, 2002, 58, 1293.

4. Safavi A, Abdollahi H and Mirzajani R, Spectrochim Acta Part A., 2006, 63, 196.

5. Mulaudzi L V, van Staden J F and Stefan R I, Anal Chim Acta, 2002, 467, 35.

6. Meddourene N, Douadi T, Chafaa S, Khan M and Bouet G, Comptes Rendus Chimie, 2004, 7, 1113.

7. Abu-Bakr M S, Sedaira H and Hashem E Y, Talanta, 1994, 41, 1669.

8. Hider R C, Bickar D, Morrison I E G and Silver J, J Am Chem Soc., 1984, 106, 6981.

9. Dash A C and Harris G M, Inorg Chem., 1982, 21, 2336.

10. Jordan R B, Inorg Chem., 1983, 22, 4160.

11. Xu J and Jordan R B, Inorg Chem., 1988, 27, 1502.

12. Goluber N S and Denisov G S, J Mol Struct., 1992, 270, 263.

13. Goluber N S, Denisov G S, Kuzina L A and Smirnov S N, Russ J Gen Chem., 1994, 64, 1162.

14. Denisov G S, Goluber N S, Schreiber V M, Shajakhmedov S S and Shurukhina AV, $J$ Mol Struct., 1996, 381, 73-81.

15. Brzyska W, Kula A, Rza czyn'ska Z and Jaroniec M, Polish J Chem., 1998, 72, 2087.

16. Brzyska W, Kula A, Rzaczyn'ska Z and Jaroniec M, Polish J Chem., 1998, 72, 2524.

17. Glowiak T, Brzyska W, Kula A, Rzaczyn'ska Z and Jaroniec M, J Coord Chem., 1999, 48, 477.

18. Griffith W P, Nogueira H I S, Parkin B C, Sheppard R N, White J P, and Williams D J, J Chem Soc Dalton Trans., 1995, 1775.

19. Bandoli G, Dolmella A, Gerber T I A, Perils J, and Preez J G H, Inorg Chim Acta, 1999, 294, 114. 
20. Cariati F, Erre L, Micera G and Panzanelli A, Inorg Chim Acta, 1983, 80, 57.

21. Smith G, Kennard C H L and Mak T C W Z, Kristallogr., 1988, 184, 275.

22. Soares-Santos P C R, Nogueira H I S, Almeida Paz F A, Sa'Ferreira R A, Carlos L D, Klinowski J and Trindade T, Eur J Inorg Chem., 2003, 3609.

23. Caritati F, L Strinna E re, Micera G, Panzanelli A and Cianni G, Inorg Chim Acta, 1983, 80, 57.

24. Mak T C W, Smith G and Kennard C H L Z, Kristallogr., 1993, 270, 33.

25. Harvey A E and Manning D L, J Am Chem Soc., 1950, 72, 4488.

26. Likussar W and Boltz D F, Anal Chem., 1971, 43, 1265.

27. Das A R and Nair V S K, J Inorg Nucl Chem., 1972, 34, 1271.

28. Benolie M J and Quevauviller P, Analyst, 1998, 123, 977.

29. Standard Methods for Examination of Water and Wastewater, $16^{\text {th }}$ Ed., APHAAWWA. WPCF, Washington, D.C, 1985. 


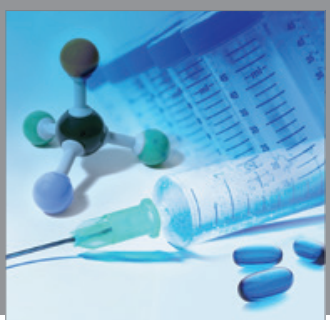

International Journal of

Medicinal Chemistry

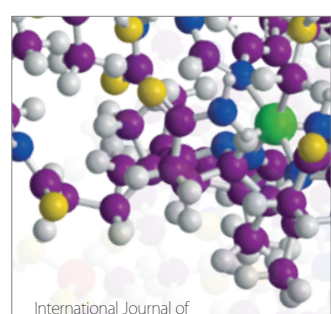

Carbohydrate Chemistry

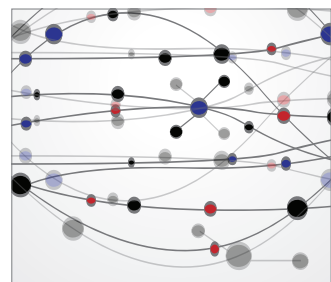

The Scientific World Journal
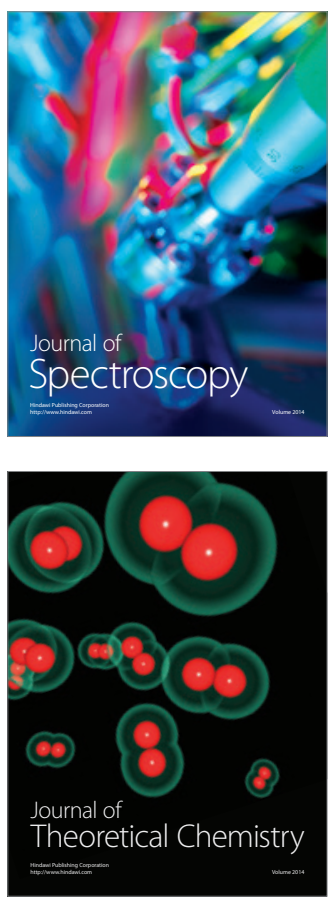
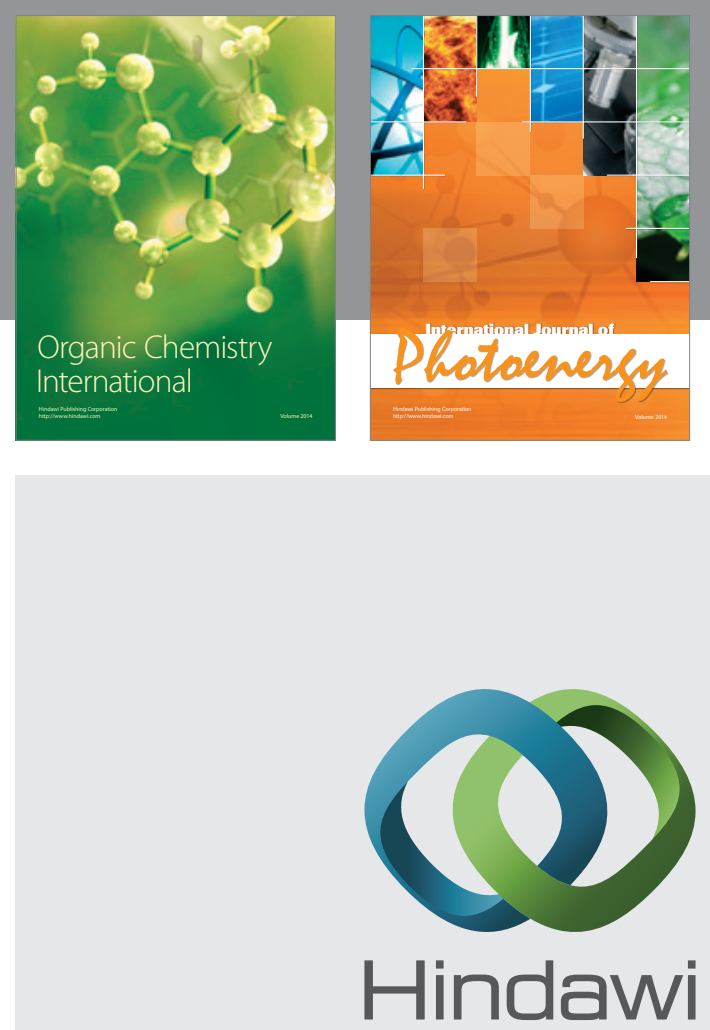

Submit your manuscripts at

http://www.hindawi.com
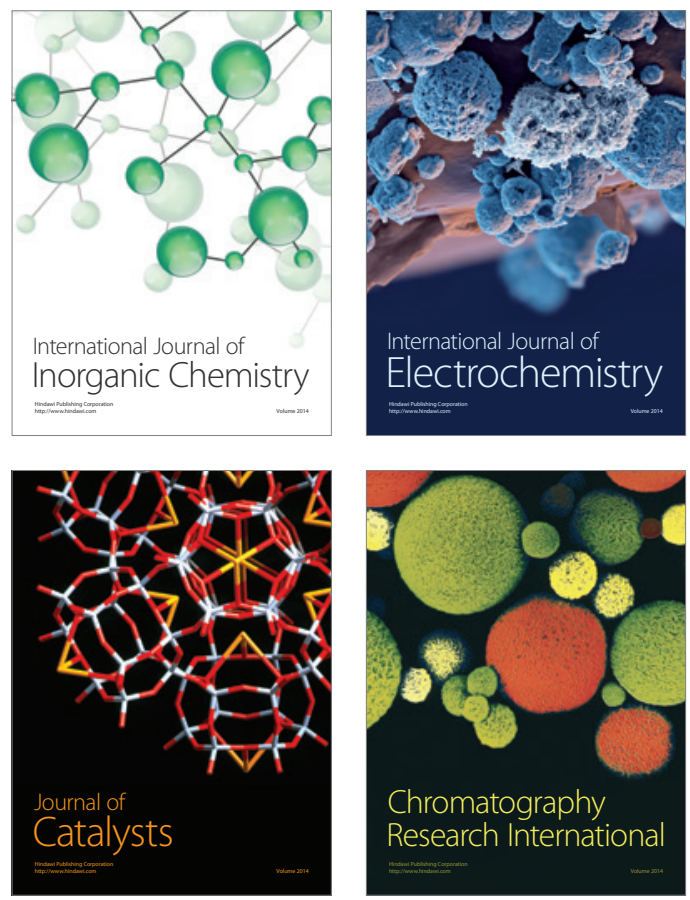
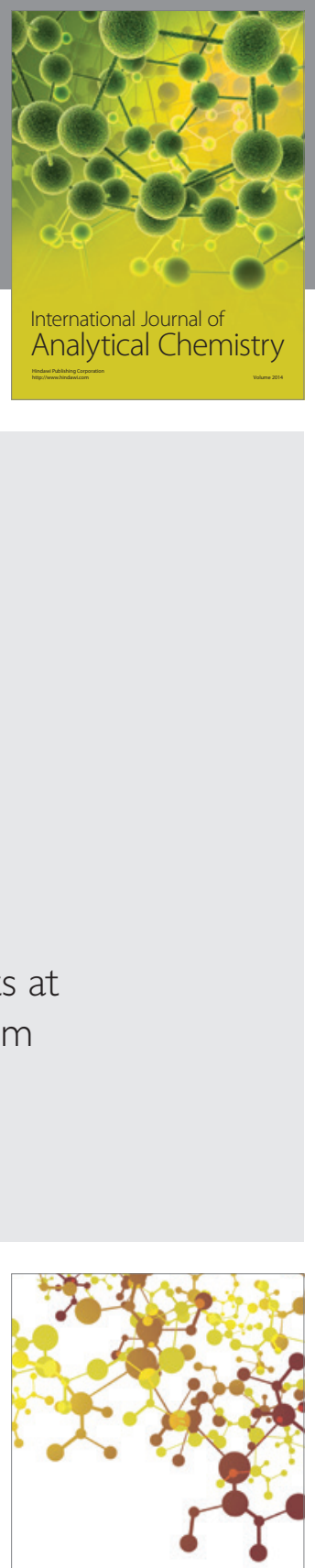

Journal of

Applied Chemistry
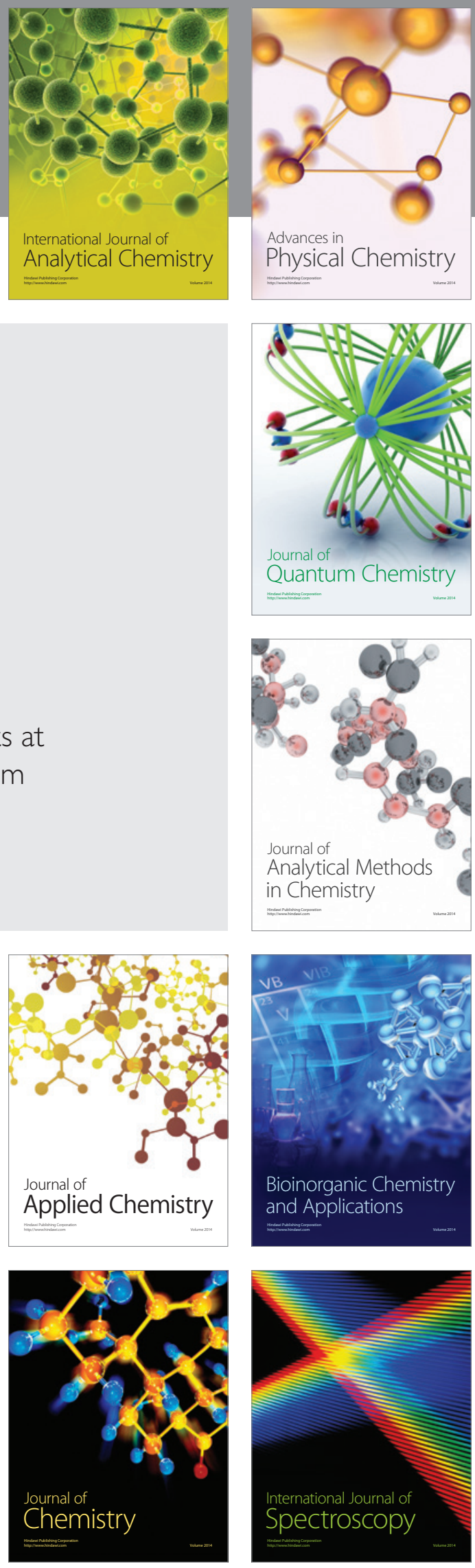